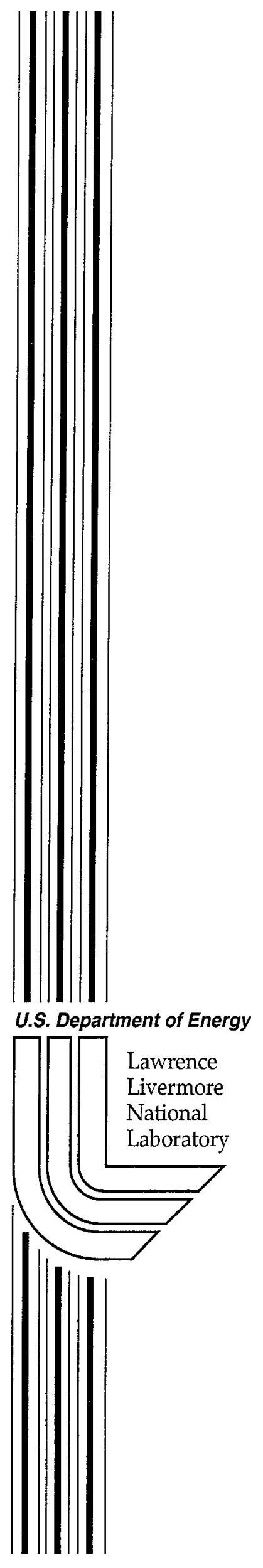

UCRL-ID-142912

\title{
Report on Explosives Repository Testing
}

\author{
L. Crouch, and J. Dotts
}

March 15, 2000 


\section{DISCLAIMER}

This document was prepared as an account of work sponsored by an agency of the United States Government. Neither the United States Government nor the University of California nor any of their employees, makes any warranty, express or implied, or assumes any legal liability or responsibility for the accuracy, completeness, or usefulness of any information, apparatus, product, or process disclosed, or represents that its use would not infringe privately owned rights. Reference herein to any specific commercial product, process, or service by trade name, trademark, manufacturer, or otherwise, does not necessarily constitute or imply its endorsement, recommendation, or favoring by the United States Government or the University of California. The views and opinions of authors expressed herein do not necessarily state or reflect those of the United States Government or the University of California, and shall not be used for advertising or product endorsement purposes.

This work was performed under the auspices of the U. S. Department of Energy by the University of California, Lawrence Livermore National Laboratory under Contract No. W-7405-Eng-48.

This report has been reproduced

directly from the best available copy.

Available to DOE and DOE contractors from the

Office of Scientific and Technical Information

P.O. Box 62, Oak Ridge, TN 37831

Prices available from (423) 576-8401

http://apollo.osti.gov/bridge/

Available to the public from the

National Technical Information Service

U.S. Department of Commerce 5285 Port Royal Rd., Springfield, VA 22161

http://www.ntis.gov/

OR

Lawrence Livermore National Laboratory

Technical Information Department's Digital Library

http:/ / www.llnl.gov/tid/Library.html 


\title{
Report on Explosives Repository Testing
}

\author{
By \\ Larry Crouch \\ \& \\ James E. Dotts \\ March 15, 2000
}

\begin{abstract}
Repositories have been in use at Lawrence Livermore National Laboratories for storage of ten grams or less explosives samples for about twenty years. A previous Repository testing program detailed in UCID 19219 reported that a standard repository would contain ten grams of high explosive but the repository drawer would open. It further recommended a non-propagating array that would allow storage of quantities of explosives in a repository drawer, however; the capability of the proposed nonpropagating array was never verified. A series of tests was undertaken to verify the capability of the proposed array to provide non-propagation between 10-gram samples stored within that array and to document the extent of damage to the stored explosives, the array and the repository.
\end{abstract}

Testing has verified that the standard four-drawer repository configured per UCID 19219 may store a 10-gram explosive sample without propagation to the other materials stored in the repository. Should a detonation of a 10-gram sample occur, the four-drawer repository will be damaged but does not appear to create a significant fragment hazard and does not sustain significant damage. The drawer containing the test charge opens quickly and fully releasing the detonation overpressure. Testing of a standard two-drawer repository verified that the array will prevent propagation, however; the repository was totally destroyed and would present a physical hazard to personnel and equipment in the immediate area of the repository.

An additional test of a standard repository was conducted to verify current storage practices for detonators using detonators in the Mound non-propagating packing configuration. The repository drawer tested sustained minimal damage and no propagation between stored detonators. Therefore, storage of detonators in a standard Mound or Manufacturer non-propagating configuration in either a two-drawer or fourdrawer repository is acceptable. 
Experimental testing of four drawer and two-drawer repositories was conducted as follows.

Test set up

a. The primary test drawer in each repository contained steel separators and foam in accordance with UCID 19219. The UCID document recommends that $3 \mathrm{~mm}$ plates be inbeded in foam and that the charges be no closer than $5 \mathrm{~mm}$ from each other. (See Photo 2)

b. The test drawer was configured with four receptor charges of 10 grams placed adjacent to a 10-gram donor charge. (See Figure $A$ and Photo 2)

c. The drawers above and below the test drawer contained one 10-gram sample directly under and over donor charge. (See Figure B and Photos $3 \& 4$ )

d. Each Receptor charge consisted of a pressed pellet of PETN, 10 grams (Note: PETN is the most sensitive of the secondary explosives currently used at LLNL)

e. Each Donor charge was C-4, a readily available, malleable secondary explosive that is less sensitive than PETN. C-4 was selected as the donor because of availability and malleability allowing easy insertion of the detonator. Total explosives weight, including the explosives in the detonator, was equal to or greater than 10 grams.

\section{Data Collection}

a. A standard speed video record was obtained for each test.

b. Still photos of each repository in test configuration were obtained before and after each test.

\section{Material and Design Requirements used during the repository tests:}

a. Two Fire King four drawer repositories and one Fire King two drawer repository were used during the test. Each repository was configured with a non-propagating array with the donor charge in the middle part of the array and receptors clustered around the periphery (See Photo \# 2). Receptor charges were place in the drawer above and below the donor drawer (See Photo \# 4).

\section{Drawer inserts:}

1. The steel was $3 \mathrm{~mm}$ thick and interlocked in an egg crate fashion. A 3-mm steel plate was placed on the bottom of each drawer.

2. The bottom of the drawer was lined with high-density building foam, as was each space in the steel egg crate.

3. A portion of the foam was removed from the center of each egg crate section to allow for explosive storage. The minimum distance between the edge foam, the explosives item, and any steel separator was at least one half inch.

b. The verification for detonator testing was conducted in the top drawer of one of the four drawer repositories. The non-propagating array for detonators is shown in Photo's \# 13 and 14. This array comes directly from the Mound suitcase and is not related to the insert array used for the 10-gram explosives test. 
c. Receptor charges 10-grams each, PETN.

d. Donor charges 10 -grams each, C-4 with detonator.

e. The repository drawer retaining pins were engaged; however, the repository lock (primary security locking mechanism) was not engaged. The primary security locking mechanism is on the top drawer; therefore, the worst-case incident would be in the drawers below the first drawer where the retaining pin is the weakest.

\section{Pass Fail Criteria Were:}

\section{IF THE REPOSITORY DRAWERS REMAIN CLOSED DURING THE TEST AND THERE IS:}

1. No propagation to any receptor - Pass

2. Propagation between donor and any receptor - Fail

\section{IF THE REPOSITORY DRAWERS COME OPEN DURING THE TEST AND THERE IS:}

1. No propagation to any receptor and no hazardous metal fragments expelled - Pass

2. Propagation to any receptor - Fail

3. Hazardous metal fragmentation outside the repository - Fail Note: For this test, receptor material, cardboard, was placed at a distance of $<5$ feet to provide an indication if harmful fragments were expelled. This distance was chosen to simulate the approximate distance between repositories and work areas. If fragments had penetrated the material at that distance the test would have been considered a failure.

\section{Additional Test of Repository for Detonator Storage}

A second set of tests, using a second four-drawer repository was conducted to verify storage of 1.4 materials in a repository as Hazard Class/Compatibility Group 1.4S. The 1.4 material used in this test was packaged in a non-propagating shipping configuration found in Mound detonator shipping containers.

Testing of 1.4 material was conducted in safe drawers using RP-1 detonators in non-propagating array.

a. Three RP-1 detonators were placed in a non-propagating array (Mound internal shipping package) as acceptor detonators. The detonators were placed one on each beside the donor detonator and one opposed (behind) the donor detonator (Photo's \# 13 and 14). An additional receptor was placed directly beneath the donor detonator with the protective plate and packing between the two.

b. The RP-1 donor detonator was functioned with the drawer closed. 


\section{Acceptable Criteria were:}

1. Non-propagation between detonators and

2. Repository drawer remains closed

Figure A

TOP VIEW

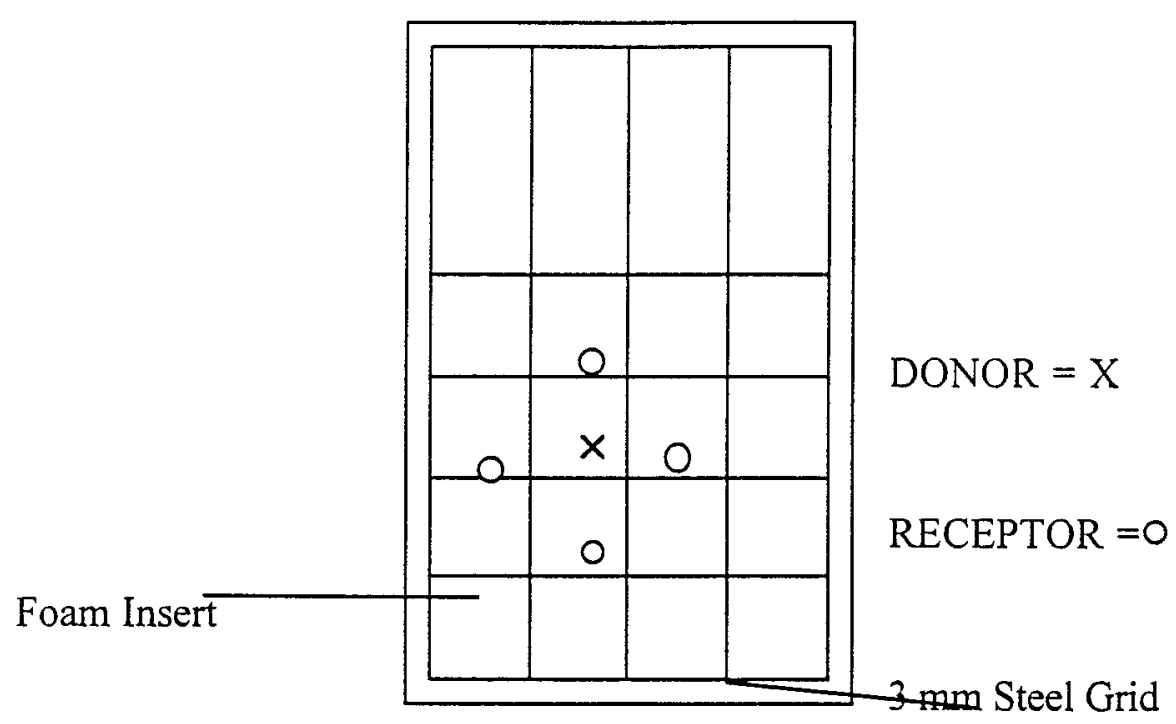

Repository Drawer Top Looking Down

RECEPTOR $=10 \mathrm{gm}$

$\mathrm{DONOR}=10 \mathrm{gm}$ 
Figure B

FRONT VIEW

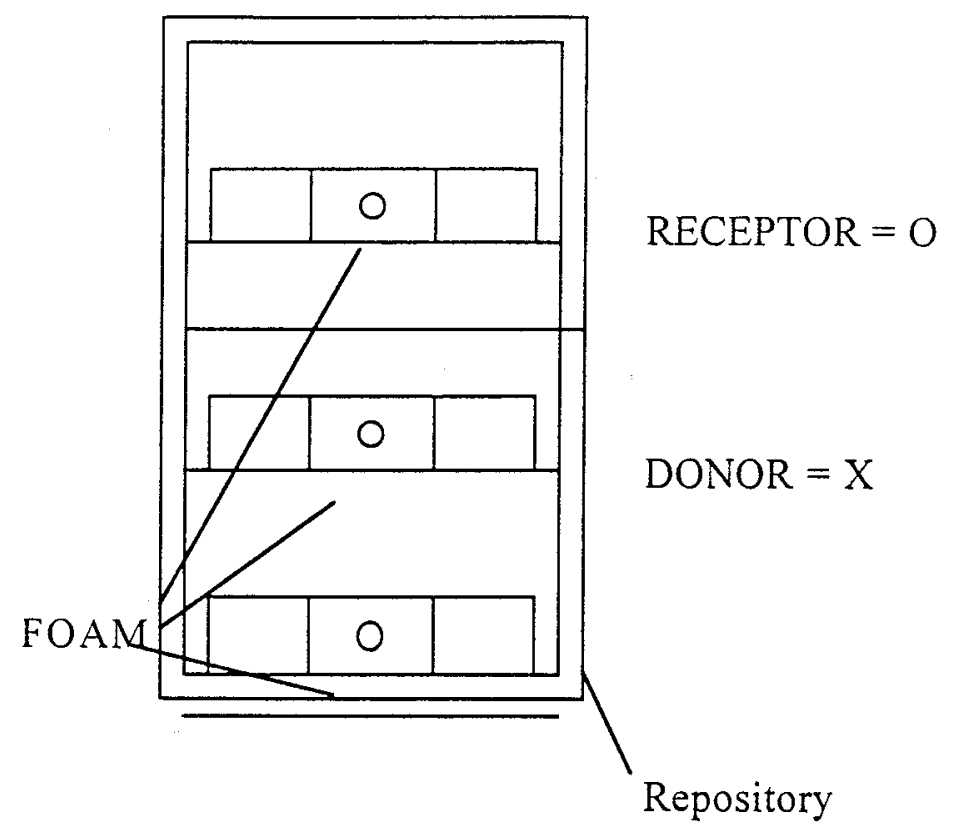

\section{RECEPTOR $=10 \mathrm{gm}$ \\ DONOR $=10 \mathrm{gm}$}

\section{Results:}

1. When 10 grams or less are stored in the array and the configuration shown in Photo \# 2 there is no propagation between items as can be seen in Photo \#9.

2. Items stored in same array and configuration in drawers above and below a drawer of occurrence will not propagate as seen in Photo \# 8 .

3. Although there is no propagation when the array and configuration in Photo \#10 is used in the two-drawer repository, the repository does not fair well as can be seen in Photo's 11 and 12. 
4. If a drawer in a four drawer repository is restrained as seen in Photo \#18, the damage resulting from an event is greater than when the drawer is not restrained as can be seen in Photo \# 19.

5. When detonators are stored in non-propagating Mound type shipping configuration, see Photo's \# 13,14 and 15, the drawer remains intact and there is no propagation from one detonator to another. See Photo \#17

\section{Conclusions:}

1. The objective of this test was to verify the non-propagation array recommend in UCID 19219. That objective has been met. Four drawer repositories configured as described in the test plan and noted in Figure A, can provided non-propagation protection for up to ten grams of high explosives. The maximum amount of explosives in one drawer should be limited to a total of 50 grams in the tested array with no more than 10 grams in each element of the array.

2. Although the two-drawer repository did not allow propagation between the donor and receptor explosives, it DID NOT provide sufficient strength and became a physical hazard when the donor charge detonated.

3. The detonator storage array using the inter-packing from Mound suitcases provides non-protection for detonator storage. As in the Mound suitcases, it is necessary to provide an Aluminum plate between the interpacks to insure non- propagation between layers.

4. Using the Mound packing, a repository drawer will sustain little damage if a single detonator functions.

5. Both four drawer and two drawer repositories can be used for storage of properly packaged detonators.

\section{Recommendations:}

1. Only four drawer repositories with a properly configured array be used for storage of $\leq 10$ grams of explosives. Total quantity of explosives allowed per drawer should be determined by requirements. Each drawer used for explosives storage shall be configured with an egg crate array made of $3 \mathrm{~mm}$ thick steel and filled with high-density foam per the attached test plan design.

2. Steel plates should be positioned under each array.

3. Two drawer repositories shall only be used for storage of detonators in approved non-propagating containers.

4. Do Not restrain drawers!

This work was performed under the auspices of the U.S. Department of Energy by the University of California, Lawrence Livermore National Laboratory under Contract No. W-7405-Eng-48. 
Fire King Repository Prior to Test

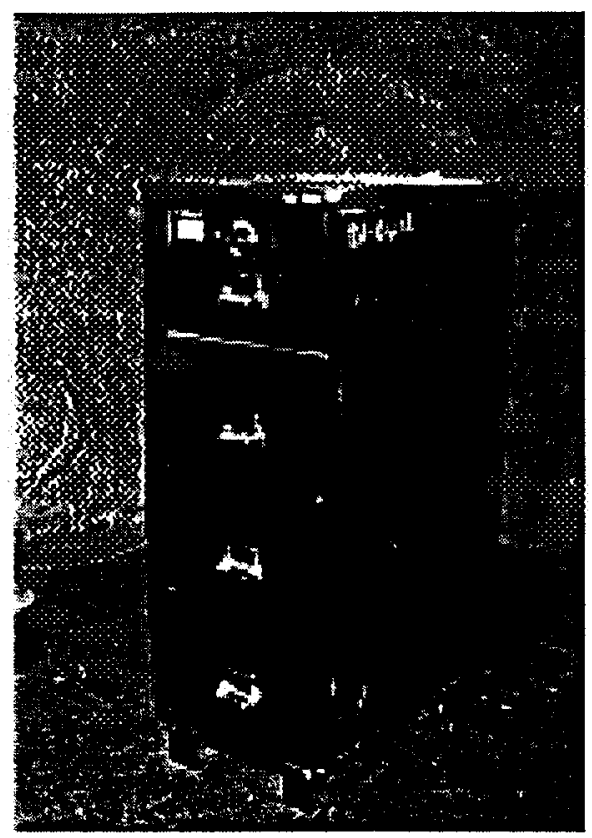

Photo 1

Top Drawer/Set Up Per

Figure B

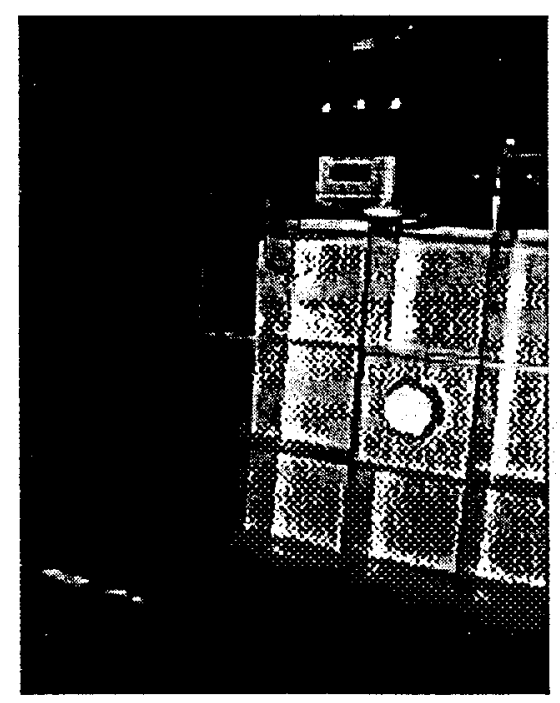

Photo 3
Drawer Set Up Per Figure A Test Plan

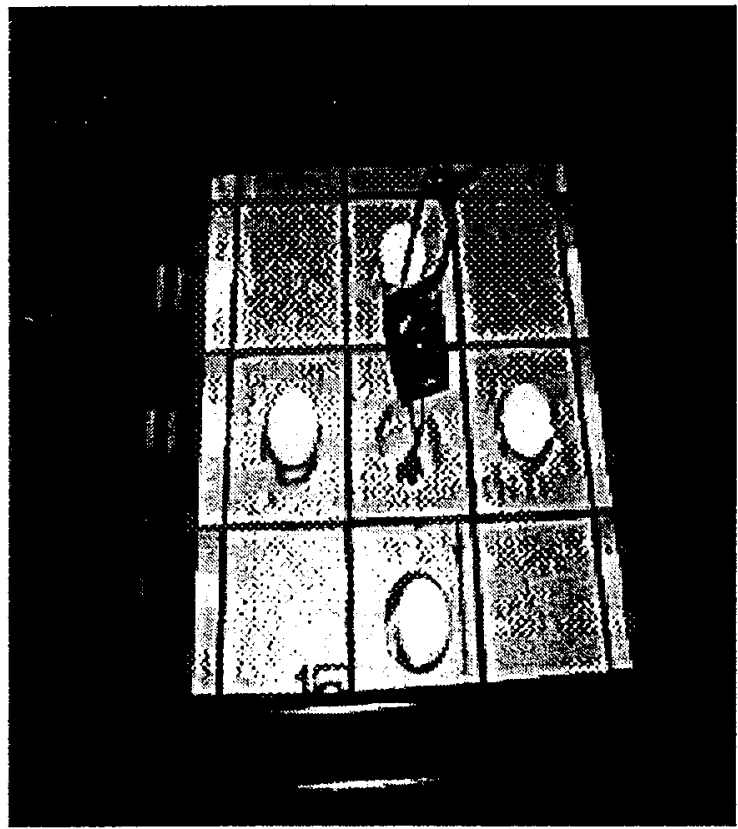

Photo 2

Bottom Drawer Per

Figure B

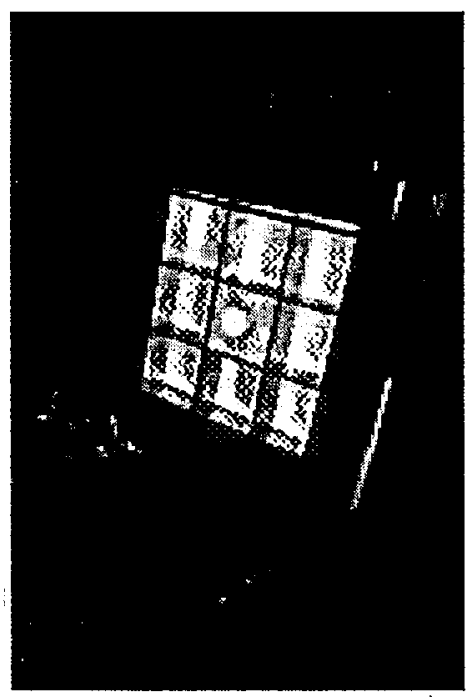

Photo 4 


\section{Four Drawer Repository after Donor Detonation}

\section{Donor Drawer}

View \#1

View \#2

No Evidence of Propagation, All Receptors Found Intact

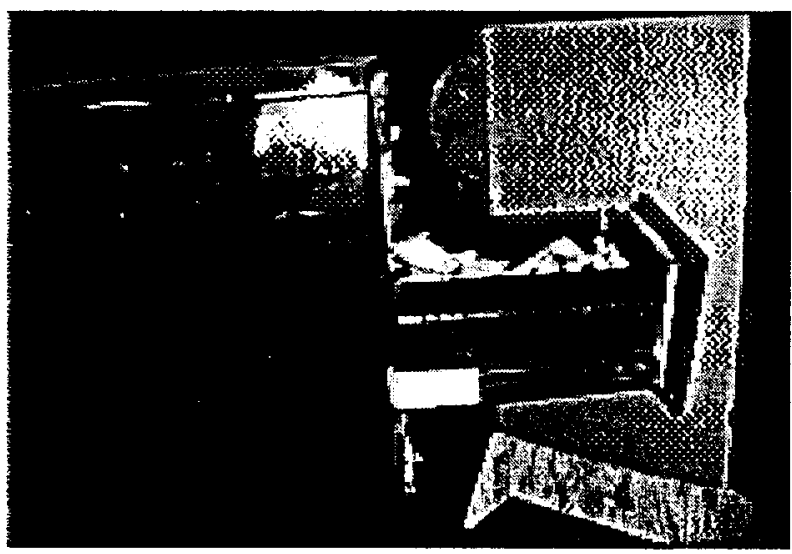

Photo 5

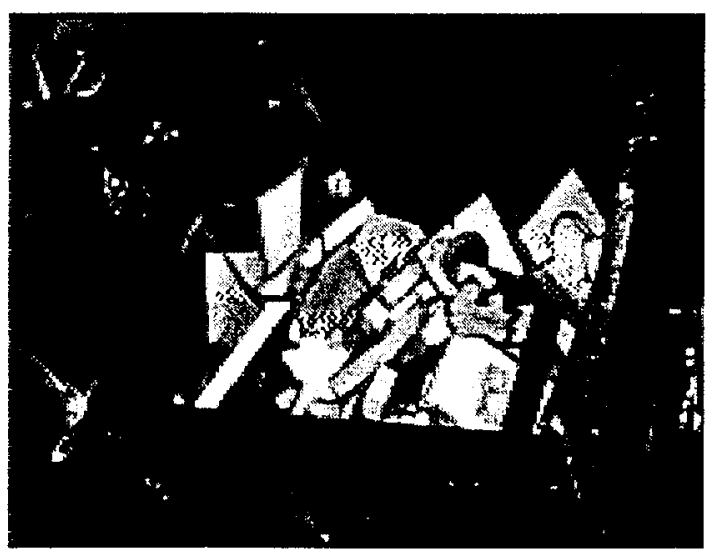

Photo 6

\section{Top and Bottom Draws after Donor Detonation}

Bottom Drawer Insulation Forced

Onto Top of the Drawer

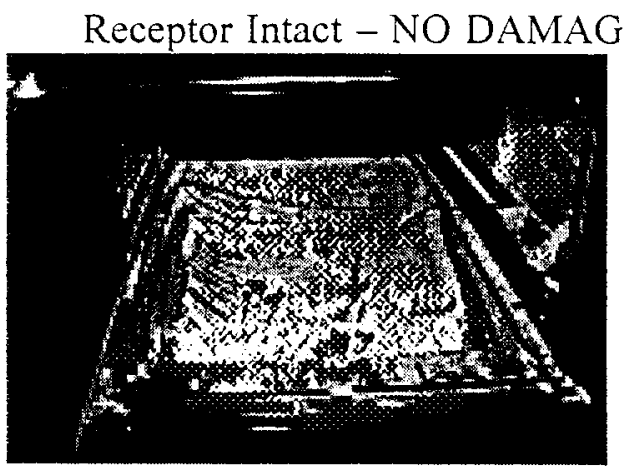

Photo 7
Top Drawer After Removal of Donor Drawer

\section{Receptor Intact - NO DAMAGE}

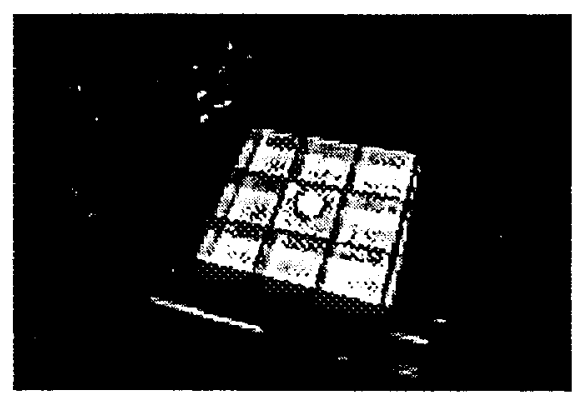

Photo 8 
Donor Drawer and Matrix

After Debris Removal

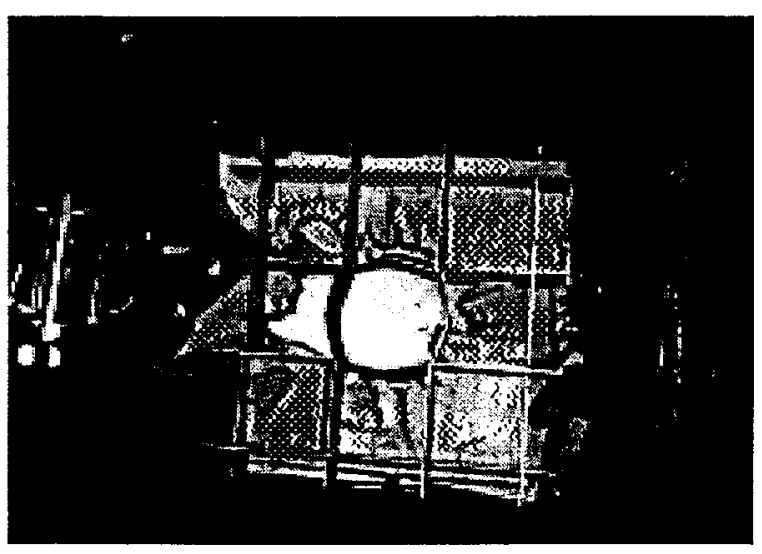

Photo 9 
Two Drawer Repository Set Up

Per Figure A

Donor Bottom Drawer

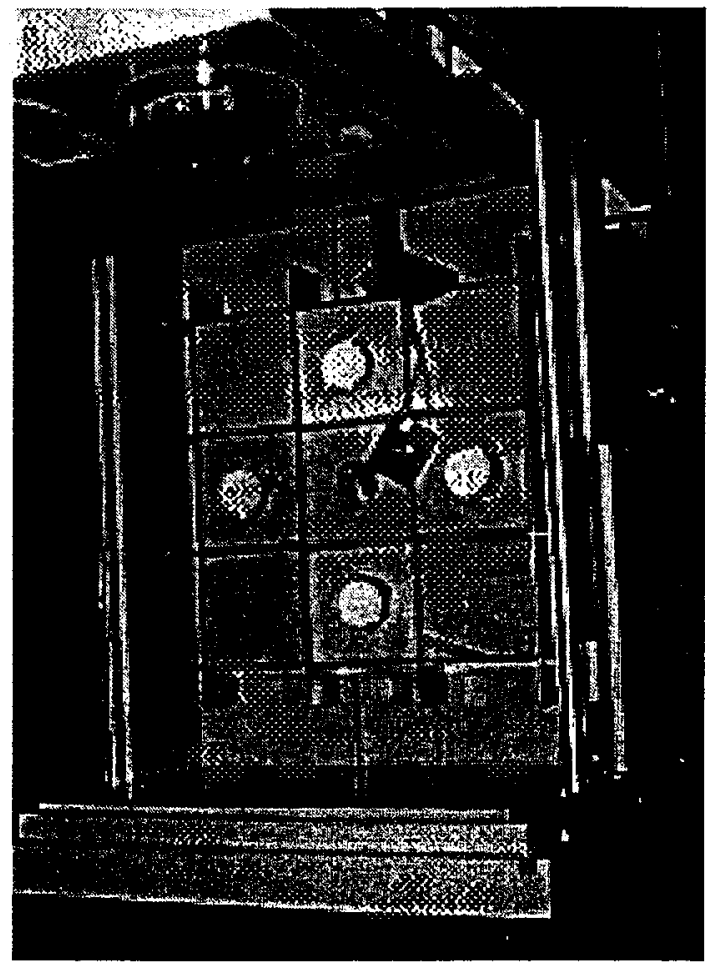

Photo 10

Two Drawer After Detonation

No Propagation

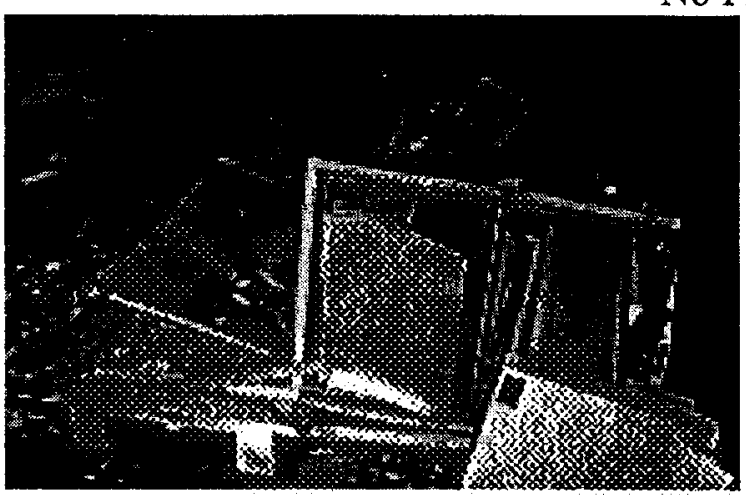

Photo 11

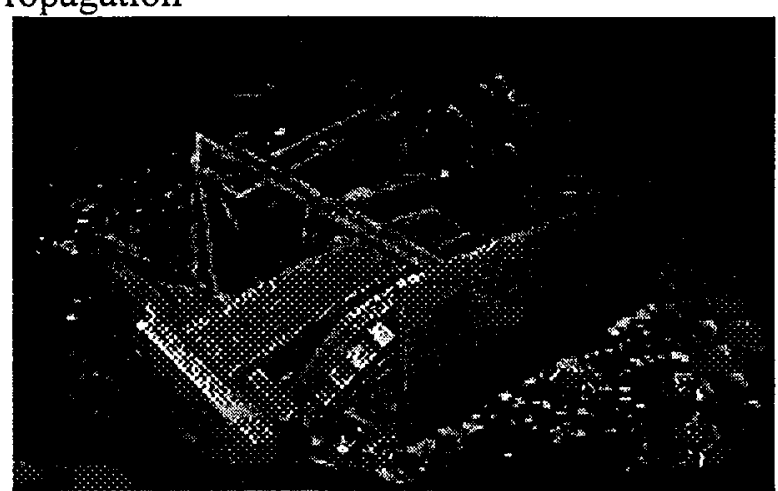

Photo 12 
Four Drawer Set Up For Detonator Test

Bottom Receptor Array

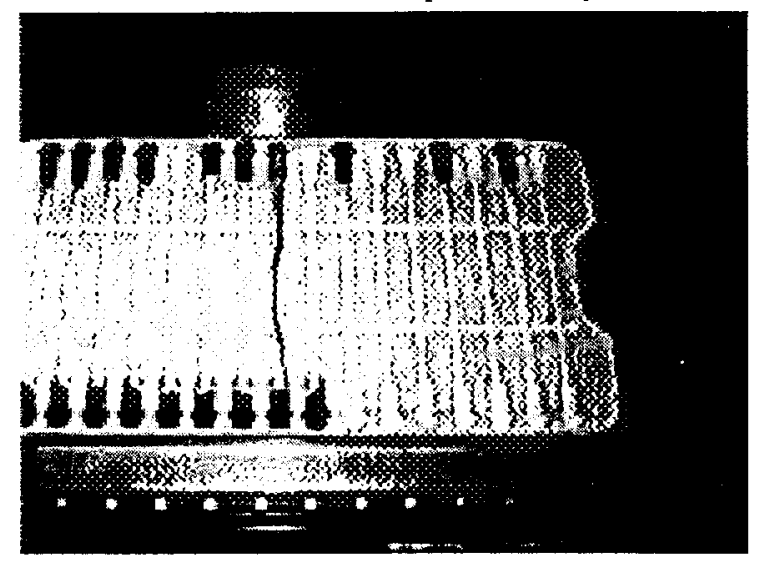

Photo 13
Top Array With Donor and Receptors

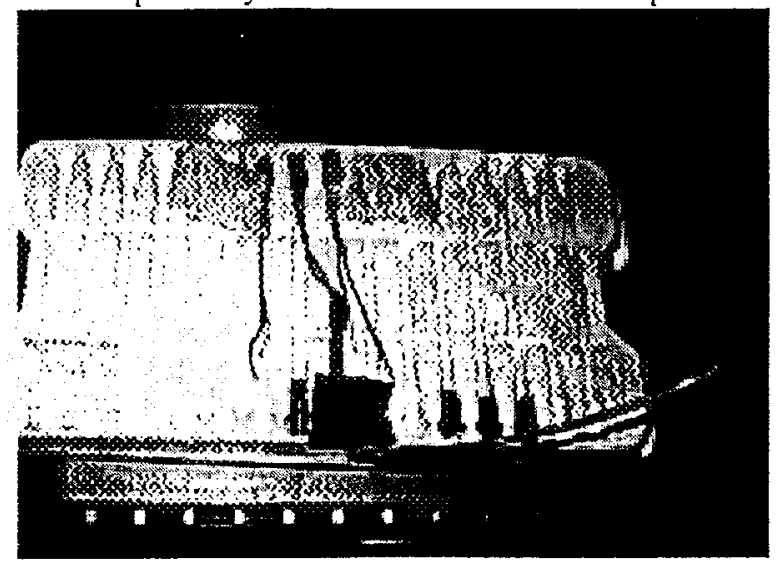

Photo 14

Normal Storage - Configuration

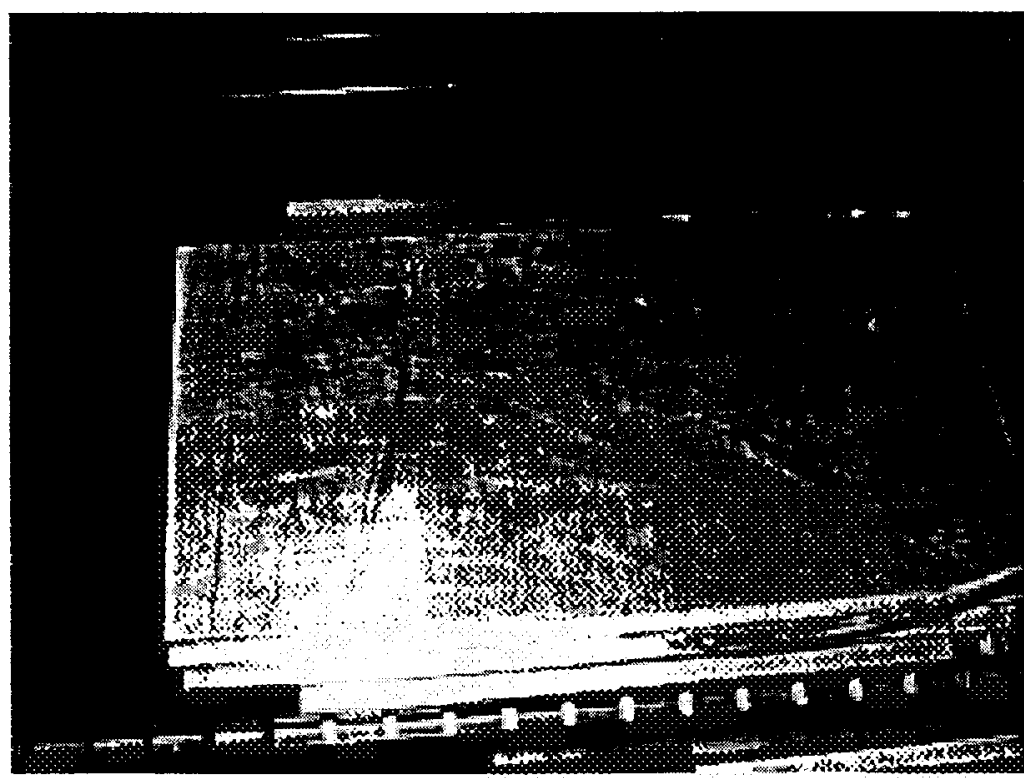

Photo 15 
Drawer After Donor Detonation

(No Propagation)

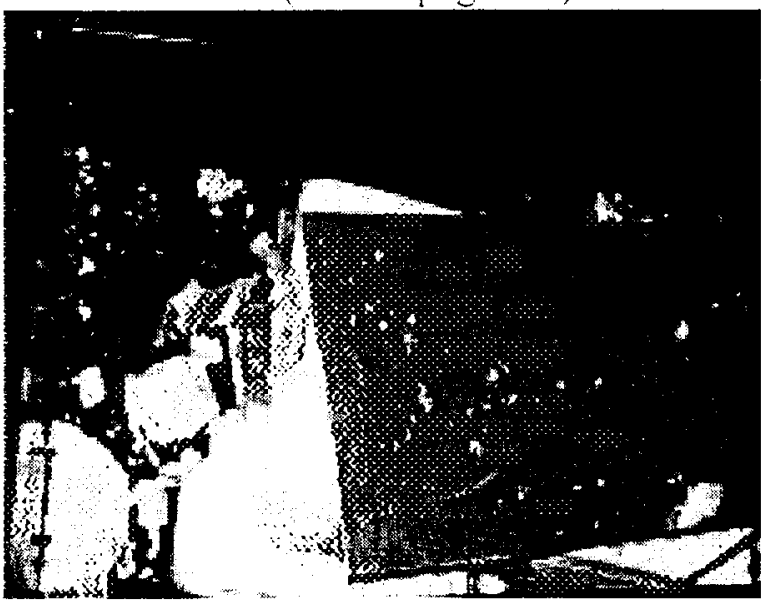

Photo 16
Bottom Receptor

(No Damage)

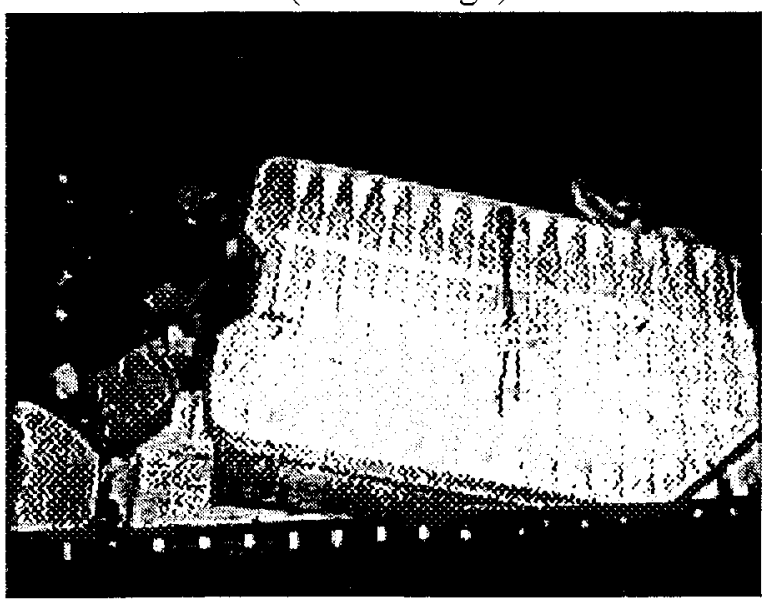

Photo 17
Four Drawer Repository $10 \mathrm{gm}$ Test Drawer

Restrained Donor in Restrained Drawer

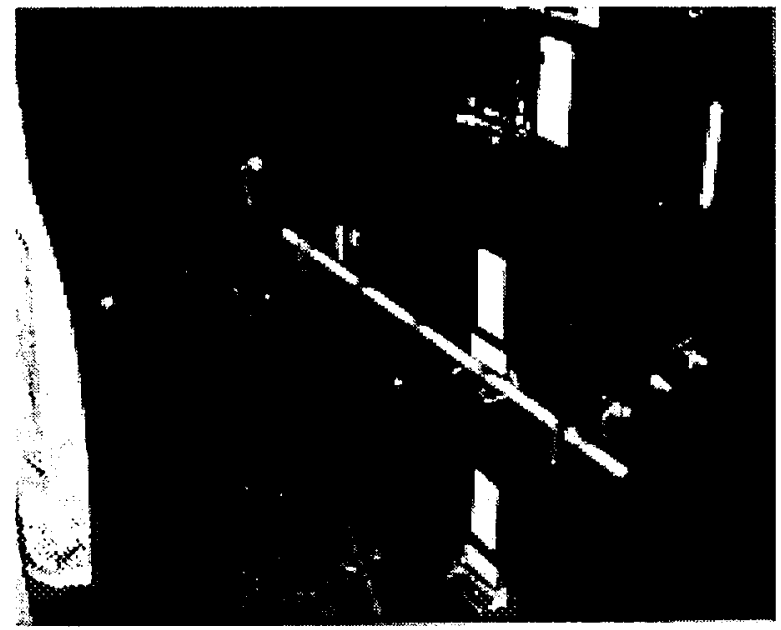

Photo 18
Four Drawer After Detonation

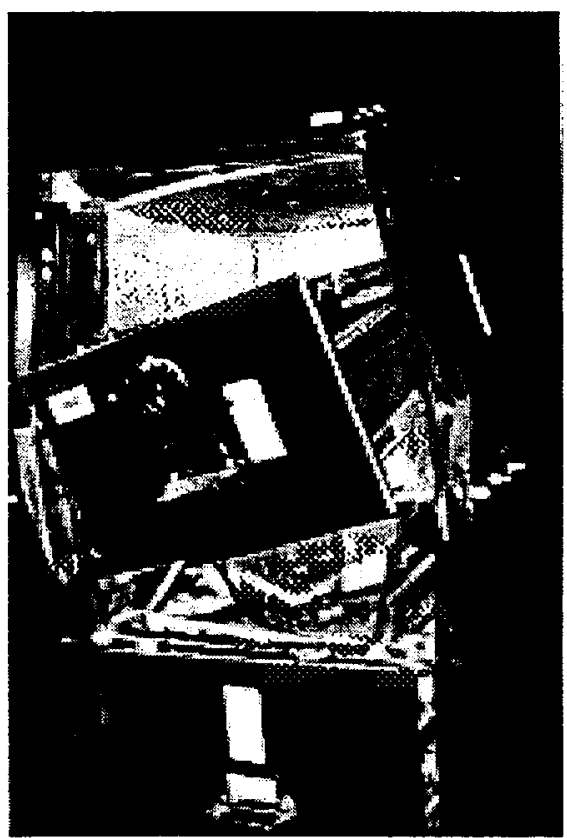

Photo 19 


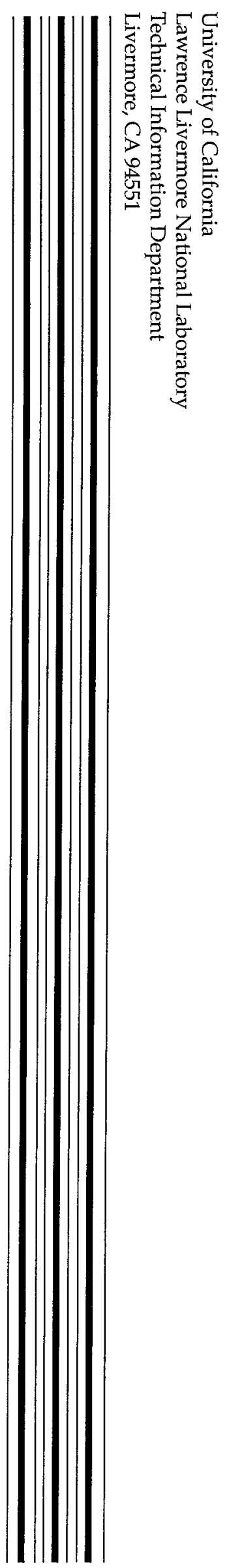

